\title{
Spectroscopic study on deuterated benzenes. II. High-resolution laser spectroscopy and rotational structure in the S[1] state.
}

\section{$\operatorname{AUTHOR(S):~}$}

Kunishige, Sachi; Katori, Toshiharu; Baba, Masaaki; Hayashi, Masato; Hasegawa, Hirokazu; Ohshima, Yasuhiro

\section{CITATION:}

Kunishige, Sachi ... [et al]. Spectroscopic study on deuterated benzenes. II. High-resolution laser spectroscopy and rotational structure in the S[1] state.. The Journal of chemical physics 2015, 143(24): 244303.

\section{ISSUE DATE:}

2015-12-28

URL:

http://hdl.handle.net/2433/207682

\section{RIGHT:}

(C) 2015 AlP Publishing. This article may be downloaded for personal use only. Any other use requires prior permission of the author and AIP Publishing. The following article may be found at http://scitation.aip.org/content/aip/journal/jcp/143/24/10.1063/1.4937950. 


\section{AIP | $\begin{aligned} & \text { The Journal of } \\ & \text { chemical Physics }\end{aligned}$}

\section{Spectroscopic study on deuterated benzenes. Il. High-resolution laser spectroscopy} and rotational structure in the $\mathrm{S} 1$ state

Sachi Kunishige, Toshiharu Katori, Masaaki Baba, Masato Hayashi, Hirokazu Hasegawa, and Yasuhiro Ohshima

Citation: The Journal of Chemical Physics 143, 244303 (2015); doi: 10.1063/1.4937950

View online: http://dx.doi.org/10.1063/1.4937950

View Table of Contents: http://scitation.aip.org/content/aip/journal/jcp/143/24?ver=pdfcov

Published by the AIP Publishing

\section{Articles you may be interested in}

Spectroscopic study on deuterated benzenes. III. Vibronic structure and dynamics in the S1 state

J. Chem. Phys. 143, 244304 (2015); 10.1063/1.4937951

Excitonic splitting and vibronic coupling in 1,2-diphenoxyethane: Conformation-specific effects in the weak coupling limit

J. Chem. Phys. 138, 204313 (2013); 10.1063/1.4807300

A femtosecond velocity map imaging study on B-band predissociation in $\mathrm{CH} 3 \mathrm{I}$. II. The 201 and 301 vibronic levels

J. Chem. Phys. 136, 074303 (2012); 10.1063/1.3683252

Torsional vibrational structure of the propene radical cation studied by high-resolution photoelectron spectroscopy

J. Chem. Phys. 135, 124310 (2011); 10.1063/1.3638182

Rotational analysis and tunnel splittings of the intermolecular vibrations of the phenol-water complex by high resolution UV spectroscopy

J. Chem. Phys. 108, 4496 (1998); 10.1063/1.475861

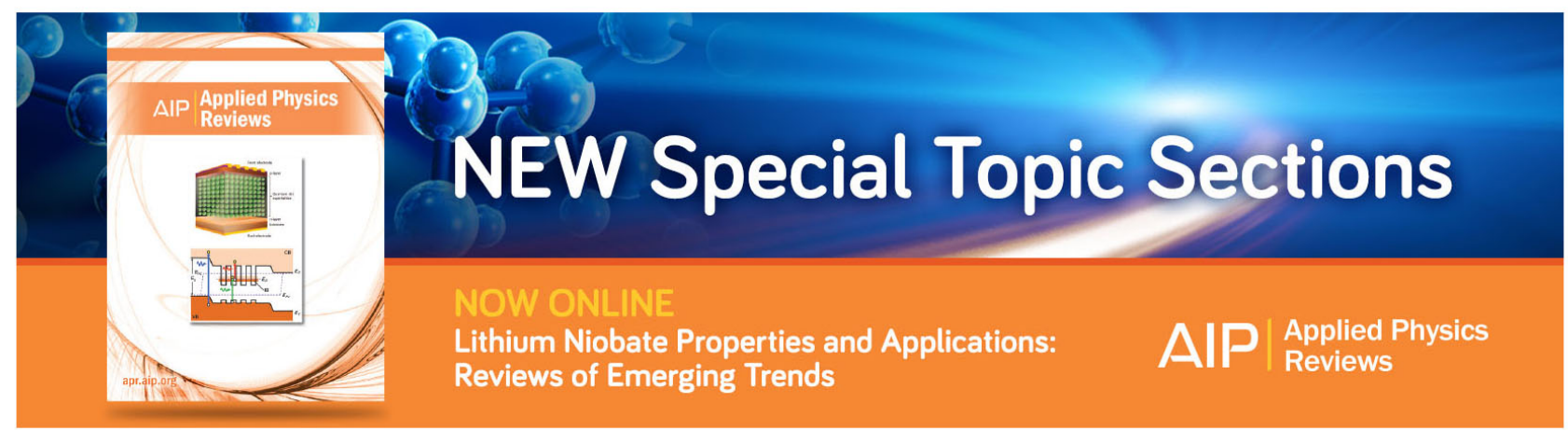




\title{
Spectroscopic study on deuterated benzenes. II. High-resolution laser spectroscopy and rotational structure in the $S_{1}$ state
}

\author{
Sachi Kunishige, ${ }^{1}$ Toshiharu Katori, ${ }^{1}$ Masaaki Baba, ${ }^{1, a)}$ Masato Hayashi, ${ }^{2}$ \\ Hirokazu Hasegawa, ${ }^{3}$ and Yasuhiro Ohshima ${ }^{2,4}$ \\ ${ }^{1}$ Division of Chemistry, Graduate School of Science, Kyoto University, Kyoto 606-8502, Japan \\ ${ }^{2}$ Institute for Molecular Science, National Institute of Natural Science, Myodaiji, Okazaki 444-8585, Japan \\ ${ }^{3}$ Department of Basic Science, Graduated School of Arts and Sciences, The University of Tokyo, Meguro-ku, \\ Tokyo 153-8902, Japan \\ ${ }^{4}$ Department of Chemistry, Graduate School of Science and Engineering, Tokyo Institute of Technology, \\ Ohokayama, Meguro-ku, Tokyo 152-8551, Japan
}

(Received 14 September 2015; accepted 2 December 2015; published online 23 December 2015)

\begin{abstract}
High-resolution spectra of the $S_{1} \leftarrow S_{0}$ transition in jet-cooled deuterated benzenes were observed using pulse dye amplification of single-mode laser light and mass-selective resonance enhanced multiphoton ionization (REMPI) detection. The vibrational and rotational structures were accurately analyzed for the vibronic levels in the $S_{1}$ state. The degenerate $6^{1}$ levels of $\mathrm{C}_{6} \mathrm{H}_{6}$ or $\mathrm{C}_{6} \mathrm{D}_{6}$ are split into $6 \mathrm{a}^{1}$ and $6 \mathrm{~b}^{1}$ in many of deuterated benzenes. The rigid-rotor rotational constants were assessed and found to be slightly different between $6 \mathrm{a}$ and $6 \mathrm{~b}$ because of different mean molecular structures. Their rotational levels are significantly shifted by Coriolis interactions. It was found that the Coriolis parameter proportionally changed with the number of substituted D atoms. (C) 2015 AIP Publishing LLC. [http://dx.doi.org/10.1063/1.4937950]
\end{abstract}

\section{INTRODUCTION}

The electronic excited states of benzene are of great interest and extensive studies using various spectroscopic methods have been performed. ${ }^{1-4}$ In Paper I, we showed that the benzene molecule was a planar regular hexagon $\left(D_{6 h}\right)$ and the structure was not changed by deuterium substitution. ${ }^{5}$ In the electronic excited state, the mean molecular structure is easily varied with adiabatic and non-adiabatic interactions. Highresolution spectroscopy is powerful for investigating such interactions and excited-state dynamics. In Paper II, we discuss the vibrational and rotational level structures of deuterated benzenes. In particular, we focus on the degenerate $v_{6}\left(e_{2 g}\right)$ mode of $\mathrm{C}_{6} \mathrm{H}_{6}$ which splits into $v_{6 \mathrm{a}}$ and $v_{6 \mathrm{~b}}$ for deuterated benzenes of lower symmetry. The degenerate $6^{1}\left(e_{2 g}\right)$ levels split into two levels of different symmetries, $6 a^{1}$ and $6 b^{1}$, in some isotopomers. It is very important to investigate systematically the vibrational and rotational structures because they vary depending on the isotopomer. The rotational structures of $\mathrm{C}_{6} \mathrm{H}_{6}$ and $\mathrm{C}_{6} \mathrm{D}_{6}$ have been completely analyzed by Sieber et al. ${ }^{6}$ and Okruss et al. ${ }^{7}$ by high-resolution laser spectroscopy. As for the partially substituted isotopomer, there has been no report other than the work on $\mathrm{C}_{6} \mathrm{H}_{5} \mathrm{D}$ by Riedle et al. ${ }^{8}$

$\mathrm{C}_{6} \mathrm{H}_{6}$ is a planar regular hexagon $\left(D_{6 h}\right)$ and possesses 10 types of degenerate vibrations. ${ }^{9,10}$ Although the $S_{1}{ }^{1} B_{2 u}$ $\leftarrow S_{0}{ }^{1} A_{1 g}$ transition is forbidden, the vibronic bands are observed by intensity-borrowing from other electronic states. ${ }^{11}$ Ultrahigh-resolution spectra $\left(\Delta E=0.0001 \mathrm{~cm}^{-1}\right)$ of the $S_{1}-S_{0}$ vibronic bands were already observed for $\mathrm{C}_{6} \mathrm{H}_{6}$ and $\mathrm{C}_{6} \mathrm{D}_{6}$, and the rotational constants and Coriolis parameter were accurately determined using a least-squares fit of a large

\footnotetext{
a) Author to whom correspondence should be addressed. Electronic mail: baba@kuchem.kyoto-u.ac.jp
}

number of spectral lines. ${ }^{6,712-14}$ For deuterated benzenes, we performed high-resolution spectroscopy with narrow-band pulsed laser light $\left(\Delta E=0.005 \mathrm{~cm}^{-1}\right)$, which was obtained by pulse dye amplification of single-mode $\mathrm{cw}$ laser light. We identified the $6_{0}^{1}$ (or $6 \mathrm{a}_{0}^{1}$ and $6 \mathrm{~b}_{0}^{1}$ ) bands of every H/D isotopomer, and determined the rigid-rotor rotational constants in the excited state. Coriolis interaction shifts the rotational levels of these degenerate or near-degenerate vibrational levels. We discuss the Coriolis parameter determined by a least-squares fit of observed spectral lines.

\section{EXPERIMENTAL}

The mixed sample of deuterated benzenes is the same as that used in Paper I. ${ }^{5}$ Here, we briefly describe the experimental setup because the details were described previously. ${ }^{15,16}$ We generated a supersonic jet with He gas at the stagnation pressure of $70 \mathrm{~atm}$. The rotational temperature was estimated to be about $1 \mathrm{~K}$. The jet was collimated using a conical skimmer and crossed with a laser beam at right angles in an ionization chamber. As a source of exciting light, we used a $\mathrm{cw}$ single-mode Ti:sapphire laser (Spectra Physics, Matisse TROB2-W, $\Delta E=0.0001 \mathrm{~cm}^{-1}$ ) pumped by a $\mathrm{Nd}^{3+}: \mathrm{YVO}_{4}$ laser (Spectra Physics, Millennia 10sJs). The output was pulse dye amplified using a pulsed laser (Spectra Physics LAB-190-10, $532 \mathrm{~nm}, \Delta t=5 \mathrm{~ns}$ ). The third harmonics was generated to excite the deuterated benzene molecules. In addition, we used a pulsed dye laser (Continuum ND6000JST, $\Delta E=0.3 \mathrm{~cm}^{-1}$ ) pumped by a pulsed $\mathrm{Nd}^{3+}$ :YAG laser (Continuum, SureliteII-10, $355 \mathrm{~nm}$ ) to ionize the excited molecules. The $\mathrm{C}_{6} \mathrm{H}_{6-\mathrm{N}} \mathrm{D}_{\mathrm{N}}^{+}$ ion was detected by a microchannel plate (MCP) detector (Galileo) through a time-of-flight tube. The transient MCP 
signal output was recorded by changing the wavelength of exciting laser light. The mass-selective resonance enhanced multiphoton ionization (REMPI) excitation spectrum was obtained by gating the signal at an appropriate flight time. The absolute wavelength of the exciting laser light was calibrated using a wavemeter (High Finesse WS-7).

\section{RESULTS AND DISCUSSION}

\section{A. Spectral analysis}

\section{1. $\mathrm{C}_{6} \mathrm{H}_{5} \mathrm{D}$}

The top of Fig. 1 illustrates a REMPI excitation spectrum detected at the mass-to-charge ratio $m / e=79$. Two bands were separately observed with the split of approximately $3 \mathrm{~cm}^{-1}$. These are two components of the degenerate vibrational levels of $v_{6}\left(e_{2 g}\right)=1$ in $\mathrm{C}_{6} \mathrm{H}_{6}$, which are split because symmetry is reduced in $\mathrm{C}_{6} \mathrm{H}_{5} \mathrm{D}$. Similar spectra were already reported by Riedle et al. ${ }^{8}$ Only a small number of rotational lines are seen because the rotational temperature is very low in this setup. However, it is difficult to accurately determine the high-order terms such as centrifugal distortion constants. We, therefore, analyzed the spectra using the following Hamiltonian of a vibrating-rotating molecule with a harmonic vibrator, rigid-rotor, and vibrational angular momentum terms ${ }^{17}$
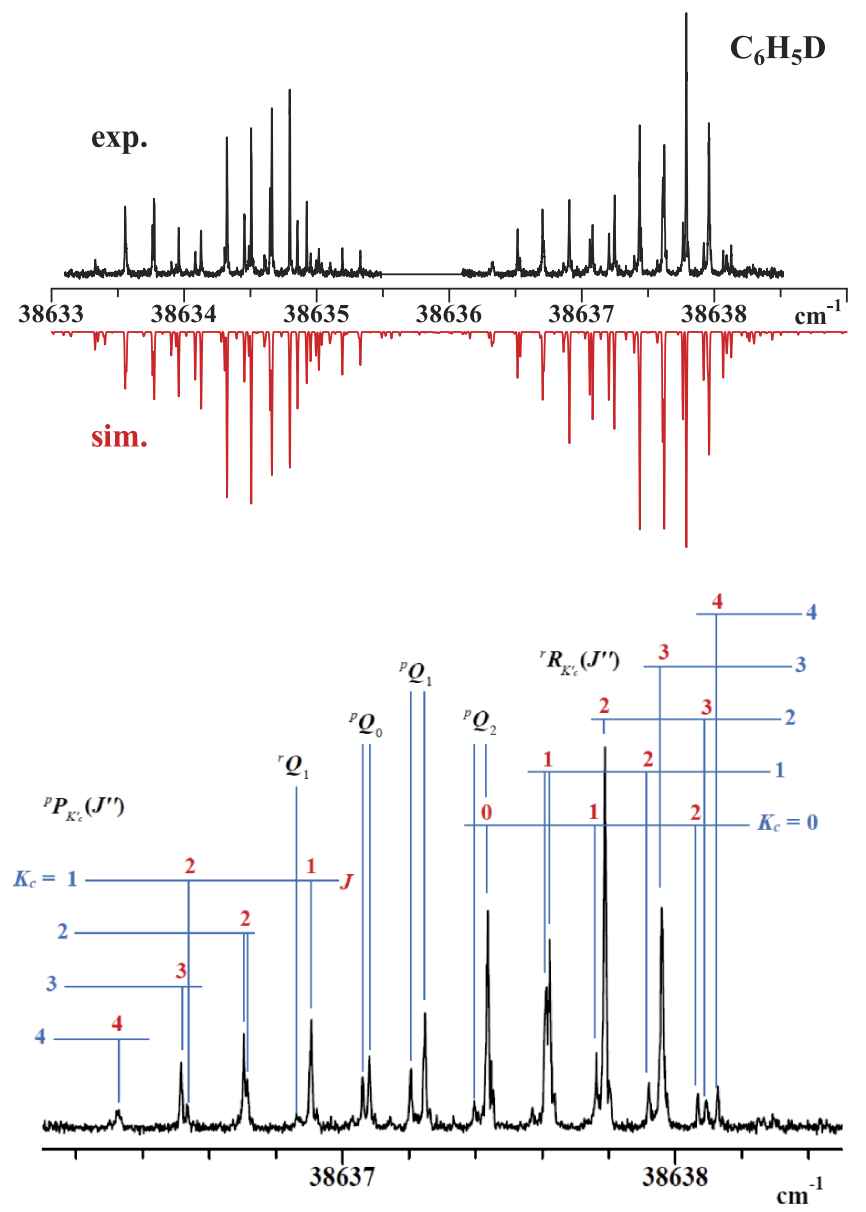

FIG. 1. REMPI excitation spectra of $6 a^{1}$ and $6 b^{1}$ bands of $\mathrm{C}_{6} \mathrm{H}_{5} \mathrm{D}$ and assignments of the rotational lines for the $6 \mathrm{a}^{1}$ band.

$$
\begin{aligned}
H= & \frac{\left(J_{x}-P_{x}\right)^{2}}{2 I_{x}}+\frac{\left(J_{y}-P_{y}\right)^{2}}{2 I_{y}}+\frac{\left(J_{z}-P_{z}\right)^{2}}{2 I_{z}} \\
& +\frac{1}{2} \sum_{r}\left(P_{r}^{2}+\lambda_{r} Q_{r}^{2}\right) .
\end{aligned}
$$

Here $Q_{r}$ and $P_{r}$ are a typical normal coordinate and its conjugate momentum, respectively. $\lambda_{r}$ is the force constant. Eq. (1) includes Coriolis interaction, which will be discussed in detail in Section III C. Although $\mathrm{C}_{6} \mathrm{H}_{5} \mathrm{D}$ is an asymmetric top (rigid rotor rotational constants $A \neq B \neq C$ ), the spectral feature is similar to that of an oblate symmetric top $(A=B>C)$. The rotational transition is represented by $\Delta K_{c} \Delta J_{K c^{\prime \prime}}\left(J^{\prime \prime}\right)$, where $J$ and $K_{c}$ are the quantum numbers of total angular momentum and its $c$-axis component, respectively. $c$ is the principal axis, which is perpendicular to the molecular plane of benzene. The $\pi \pi^{*}$ transition moment is perpendicular to this $c$ axis, and the selection rules are $\Delta J=0, \pm 1$ and $\Delta K_{c}= \pm 1$. As shown at the bottom of Fig. 1, the main lines are assigned to ${ }^{p} R_{K_{c}^{\prime \prime}}\left(J^{\prime \prime}\right),{ }^{r} R_{K_{c}^{\prime \prime}}\left(J^{\prime \prime}\right),{ }^{p} Q_{K_{c}^{\prime \prime}}\left(J^{\prime \prime}\right),{ }^{r} Q_{K_{c}^{\prime \prime}}\left(J^{\prime \prime}\right),{ }^{p} P_{K_{c}^{\prime \prime}}\left(J^{\prime \prime}\right)$, and ${ }^{r} P_{K_{c}^{\prime \prime}}\left(J^{\prime \prime}\right)$.

The rotational constants in the ground state were accurately determined by Oldani and Bauder. ${ }^{18}$ Although we also determined these values using the mean molecular structure, which is given in Paper $\mathrm{I},{ }^{5}$ our values were almost identical to their values. In this spectral analysis, we used our values and determined the rotational constants at the $6 \mathrm{a}$ and $6 \mathrm{~b}$ vibrational levels in the $S_{1}$ state by a least-squares fit using the PGOPHER program. ${ }^{19}$ The resultant values are tabulated in Table I. The rotational constants were found to be slightly different between $6 \mathrm{a}$ and $6 \mathrm{~b}$. The normal coordinates are illustrated in Fig. 2. The mean molecular structures are expected to be different in these two levels because the mean bond lengths are generally larger than the equilibrium bond lengths because of anharmonicity. ${ }^{20,21}$

It is difficult to accurately estimate the molecular structure and vibrational energies of $6 \mathrm{a}$ and $6 \mathrm{~b}$. We therefore identified these bands referring to the results of theoretical calculations using the Gaussian 09 program package. ${ }^{22}$ For all isotopomers, we calculated vibrational energies of $v_{6}$ by $\operatorname{TDDFT}(\mathrm{B} 3 \mathrm{LYP}) / 6-31++\mathrm{G}(\mathrm{d}, \mathrm{p})$ without considering anharmonicity. The resultant energies are scaled by 0.983 . The calculations indicated that the $6 \mathrm{a}$ vibrational energy was about $3 \mathrm{~cm}^{-1}$ smaller than $6 \mathrm{~b}$.

\section{2. $\mathrm{C}_{6} \mathrm{H}_{4} \mathrm{D}_{2}$}

The high-resolution spectra of $\mathrm{C}_{6} \mathrm{H}_{4} \mathrm{D}_{2}(m / e=80)$ are shown in Fig. 3. We found three series of $6 \mathrm{a}$ and $6 \mathrm{~b}$ bands with the splits of about 2.2 and $5 \mathrm{~cm}^{-1}$, respectively. There are three isotopomers for $\mathrm{C}_{6} \mathrm{H}_{4} \mathrm{D}_{2}$, which are expressed as ortho, meta, and para (Fig. 2). The results of theoretical calculations for band splitting were $2.0,2.0$, and $5.3 \mathrm{~cm}^{-1}$, respectively. The band observed in the higher energy region around $38669 \mathrm{~cm}^{-1}$ is easily identified to originate from $p-\mathrm{C}_{6} \mathrm{H}_{4} \mathrm{D}_{2}$. Two other series are mostly overlapped in the same energy region. We assigned their rotational lines by referring to the calculated rotational constants for $o-\mathrm{C}_{6} \mathrm{H}_{4} \mathrm{D}_{2}$ and $m-\mathrm{C}_{6} \mathrm{H}_{4} \mathrm{D}_{2}$. Part of the expanded spectrum is shown with the assignments at the bottom of Fig. 3. The selection rules 
TABLE I. Rotational constants $\left(\mathrm{cm}^{-1}\right)$ in the $6^{1}\left(\right.$ or $6 \mathrm{a}^{1}$ and $\left.6 \mathrm{~b}^{1}\right)$ levels in the $S_{1}$ states of deuterated isotopomers.

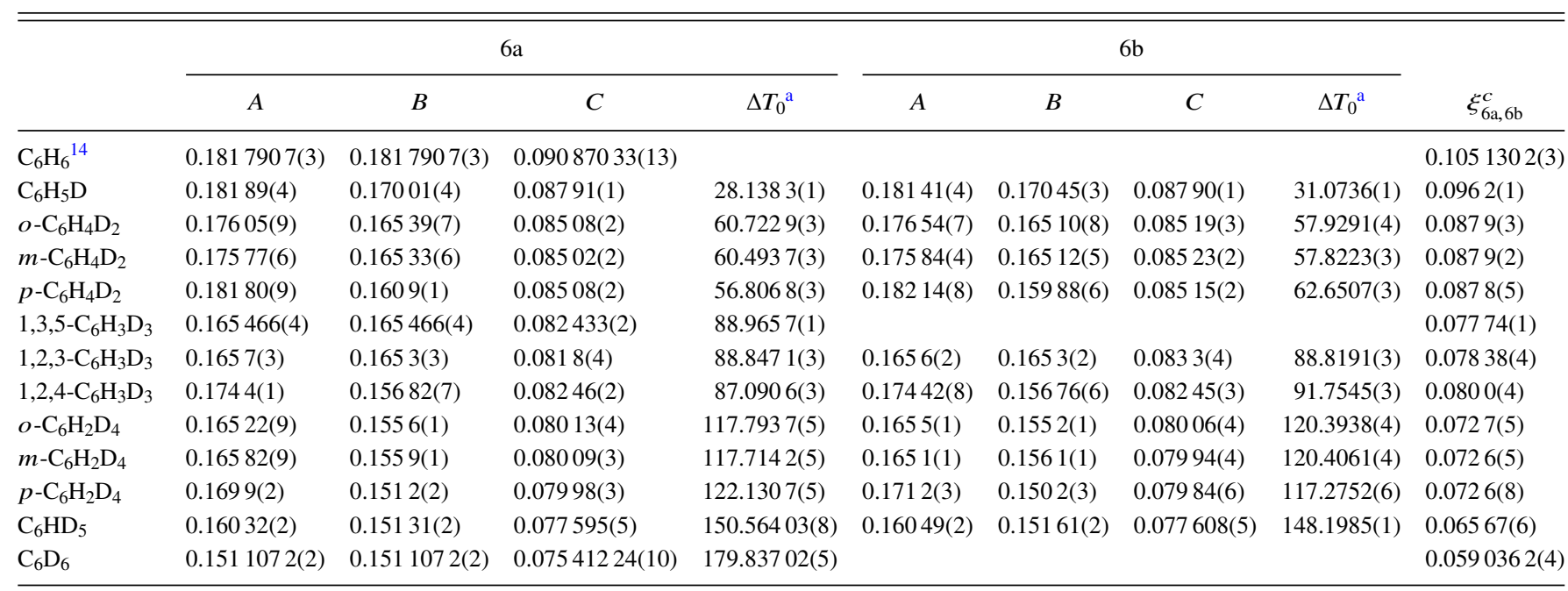

${ }^{\mathrm{a}} \Delta T_{0}\left(\mathrm{~cm}^{-1}\right)=T_{0}^{\prime}-T_{0}\left(\mathrm{C}_{6} \mathrm{H}_{6}\right)=T_{0}^{\prime}-38606.1025$. Here, $T_{0}\left(\mathrm{C}_{6} \mathrm{H}_{6}\right)$ is the rotationless origin of $6_{0}^{1}$ band of $\mathrm{C}_{6} \mathrm{H}_{6}$, and $T_{0}^{\prime}$ represents the rotationless band origin of each band.

for rotational transition are identical to those of $\mathrm{C}_{6} \mathrm{H}_{5} \mathrm{D}$. The abundance ratio is considered to be ortho:meta:para $=2: 2: 1$ because the sample mixture $(H: D=1: 1)$ is within the statistical limit distribution after exchange reaction of sufficiently long time.

\section{3. $\mathrm{C}_{6} \mathrm{H}_{3} \mathrm{D}_{3}$}

Fig. 4 shows the high-resolution REMPI excitation spectrum of $\mathrm{C}_{6} \mathrm{H}_{3} \mathrm{D}_{3}(m / e=81)$ and its simulation. We found three series of bands, which correspond to the three isotopomers of $\mathrm{C}_{6} \mathrm{H}_{3} \mathrm{D}_{3}$ shown in Fig. 5. One series was split into two bands with the peaks at 38693.3 and $38698.4 \mathrm{~cm}^{-1}$. We performed theoretical calculations of vibrational energies, and the resultant band splits were $0.1,3.9$, and $0 \mathrm{~cm}^{-1}$ for $1,2,3-\mathrm{C}_{6} \mathrm{H}_{3} \mathrm{D}_{3}, 1,2,4-\mathrm{C}_{6} \mathrm{H}_{3} \mathrm{D}_{3}$, and $1,3,5-\mathrm{C}_{6} \mathrm{H}_{3} \mathrm{D}_{3}$, respectively. The above series which has large splitting, therefore, is easily assigned to $1,2,4-\mathrm{C}_{6} \mathrm{H}_{3} \mathrm{D}_{3}$. The other two series are severely overlapped in the center region, and we could not assign the observed rotational lines. We therefore observed the high-resolution spectrum using the pure sample of $1,3,5-\mathrm{C}_{6} \mathrm{H}_{3} \mathrm{D}_{3}$. In this case, we reduced the He stagnation pressure $(10 \mathrm{~atm})$ to raise the rotational temperature and observe many transitions for high $J^{\prime \prime}$ and $K^{\prime \prime}$ levels. The result is shown in Fig. 6.

The contour is remarkably different from that of the typical perpendicular band of an oblate symmetric top that results from the energy shift by Coriolis interaction in the upper levels, about $1.0 \mathrm{~cm}^{-1}$ in maximum among the observed shifts. The statistical weights of nuclear spin states are tabulated in the Appendix, and we estimated the relative intensities of rotational lines assuming a temperature of $3 \mathrm{~K}$. The simulation shown in Fig. 6 is in good agreement with the observed spectrum. The rotational lines of $1,2,3-\mathrm{C}_{6} \mathrm{H}_{3} \mathrm{D}_{3}$ could also be assigned because those of $1,3,5-\mathrm{C}_{6} \mathrm{H}_{3} \mathrm{D}_{3}$ were identified by the above analysis. We thus determined the rotational constants and Coriolis parameters of all $\mathrm{C}_{6} \mathrm{H}_{3} \mathrm{D}_{3}$ isotopomers, which are tabulated in Table I.

\section{B. Band origins and rotational constants}

Because the spectral features of $\mathrm{C}_{6} \mathrm{H}_{2} \mathrm{D}_{4}$ and $\mathrm{C}_{6} \mathrm{HD}_{5}$ were analogous to those of $\mathrm{C}_{6} \mathrm{H}_{4} \mathrm{D}_{2}$ and $\mathrm{C}_{6} \mathrm{H}_{5} \mathrm{D}$, respectively, we did not describe the analysis procedure in detail. We can determine the band origins of $S_{1} \leftarrow S_{0} 6 \mathrm{a}_{0}^{1}$ and $6 \mathrm{~b}_{0}^{1}$ bands, rigid-rotor rotational constants, and Coriolis parameters for deuterated benzene isotopomers. The results are listed in Table I.

The degenerate $6^{1}\left(e_{2 g}\right)$ vibrational levels of $\mathrm{C}_{6} \mathrm{H}_{6}$ split into two different energy levels because of reduced symmetry that results from deuterium substitution. We express them as $6 \mathrm{a}$ and $6 \mathrm{~b}$, of which the energy difference $\Delta E_{\mathrm{a}-\mathrm{b}}$ is $2-5 \mathrm{~cm}^{-1}$. We define $6 \mathrm{a}$ and $6 \mathrm{~b}$ by the normal coordinates, as shown in Fig. 2. The relative energies depend on the isotopomers. The rotational constants are appreciably different between the $6 \mathrm{a}$ and $6 \mathrm{~b}$ levels. This is attributed to their different mean molecular structures, which depend on the change in bond lengths that results from anharmonicity in the potential energy. ${ }^{20}$

\section{Coriolis parameters}

Coriolis interactions about the $z$ axis (out of plane) occur on the rotational levels of degenerate $v_{6}$ vibrations or near-degenerate $v_{6 \mathrm{a}}$ and $v_{6 \mathrm{~b}}$ vibrations. We consider an approximate treatment of the experimental results. ${ }^{17}$ The vibrational angular momentum about the $z$ axis is generally given by

$$
P_{z}=-\sum_{n} i \hbar\left[x_{n}\left(\frac{\partial}{\partial y_{n}}\right)-y_{n}\left(\frac{\partial}{\partial x_{n}}\right)\right]
$$

where $x_{n}$ and $y_{n}$ are the mass-adjusted Cartesian displacement coordinates of the atom $n$. They are defined by

$$
x_{n}=\sqrt{m_{n}} X_{n}, y_{n}=\sqrt{m_{n}} Y_{n},
$$

where $m_{n}$ is the atomic mass. $X_{n}$ and $Y_{n}$ are dimensionless parameters, which are the atomic displacement coordinates divided by normal vibrational coordinates. The vibrational 


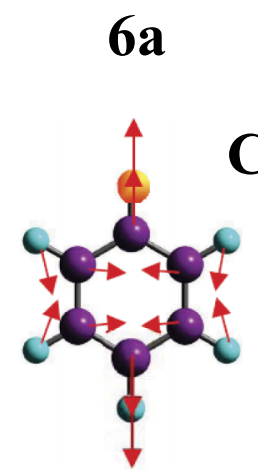

$6 \mathbf{b}$

$\mathrm{C}_{6} \mathrm{H}_{5} \mathrm{D}$
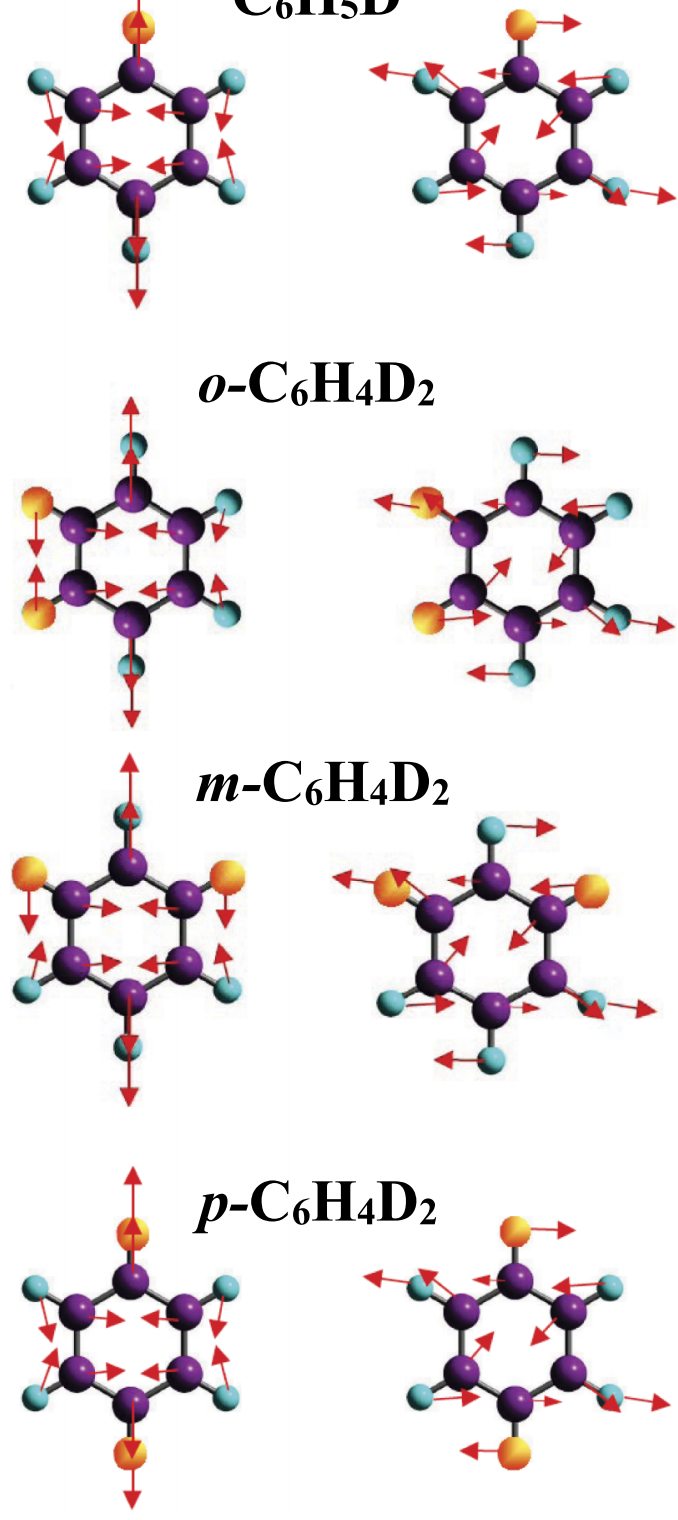

FIG. 2. Normal coordinates of $6 \mathrm{a}$ and $6 \mathrm{~b}$ vibrations of $\mathrm{C}_{6} \mathrm{H}_{5} \mathrm{D}$ and three $\mathrm{C}_{6} \mathrm{H}_{4} \mathrm{D}_{2}$ isotopomers.

angular momentum is also expressed in terms of the normal coordinates of $r$ and $s$ modes,

$$
P_{z}=\sum_{r} \sum_{s} \zeta_{r, s}^{z}\left[Q_{r} P_{s}-Q_{s} P_{r}\right] .
$$

Although the sums are generally taken over all possible combinations of $Q_{r}$ and $Q_{s}$, only the sums for the combination of $Q_{6 \mathrm{a}}$ and $Q_{6 \mathrm{~b}}$ were used. The Coriolis zeta constant is defined by

$$
\zeta_{r, s}^{z}=\sum_{n}\left[\left(\frac{\partial x_{n}}{\partial Q_{r}}\right)\left(\frac{\partial y_{n}}{\partial Q_{s}}\right)-\left(\frac{\partial x_{n}}{\partial Q_{s}}\right)\left(\frac{\partial y_{n}}{\partial Q_{r}}\right)\right] .
$$

The sign of $\zeta_{r, s}^{z}$ depends on the choice of sense of $Q_{r}$ and $Q_{s}$, and the order of $r$ and $s$.
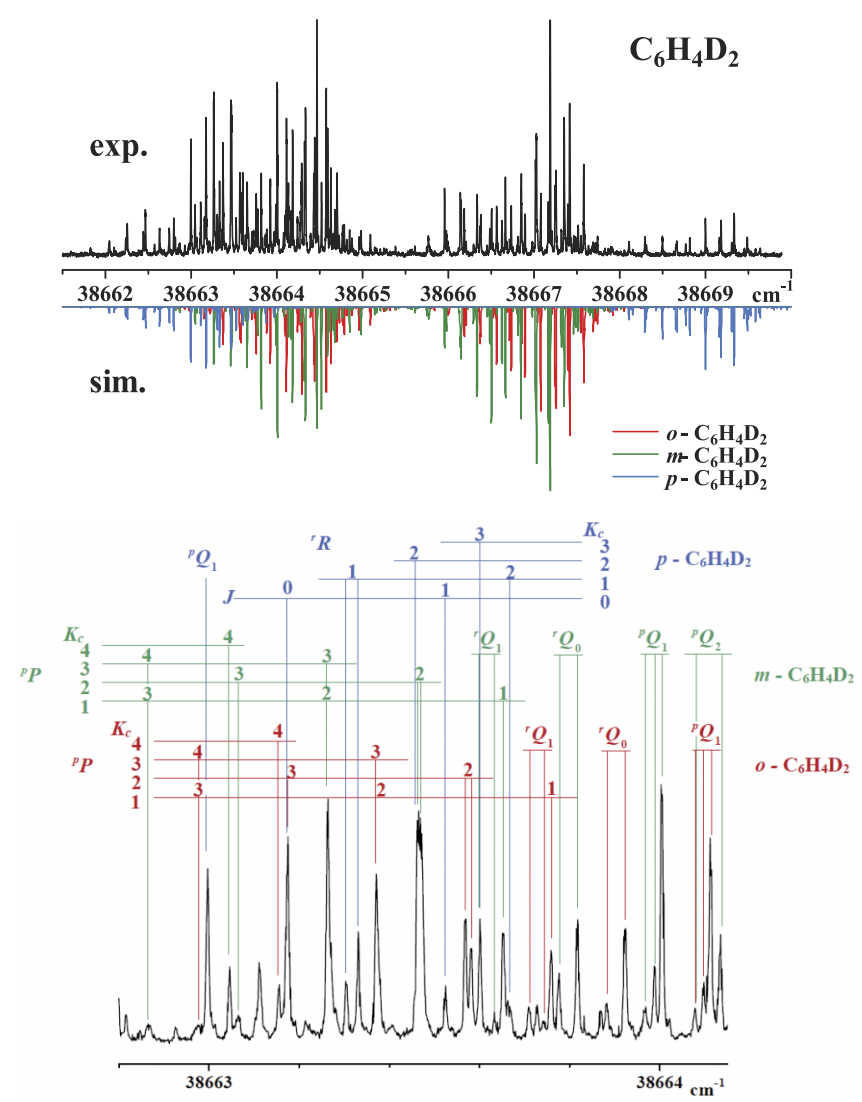

FIG. 3. REMPI excitation spectra of $6 a^{1}$ and $6 b^{1}$ bands of $\mathrm{C}_{6} \mathrm{H}_{4} \mathrm{D}_{2}$, and expanded spectrum and their assignments.

For a pair of normal coordinate of degenerate or neardegenerate vibrational modes $6 \mathrm{a}$ and $6 \mathrm{~b}$, the Coriolis zeta constant is given by

$$
\zeta_{6 \mathrm{a}, 6 \mathrm{~b}}^{z}=\sum_{n}\left[\left(\frac{\partial x_{n}}{\partial Q_{6 \mathrm{a}}}\right)\left(\frac{\partial y_{n}}{\partial Q_{6 \mathrm{~b}}}\right)-\left(\frac{\partial x_{n}}{\partial Q_{6 \mathrm{~b}}}\right)\left(\frac{\partial y_{n}}{\partial Q_{6 \mathrm{a}}}\right)\right] .
$$

The Hamiltonian (Eq. (1)) consists of three terms

$$
H=H_{v}+H_{r}+H^{\prime} .
$$

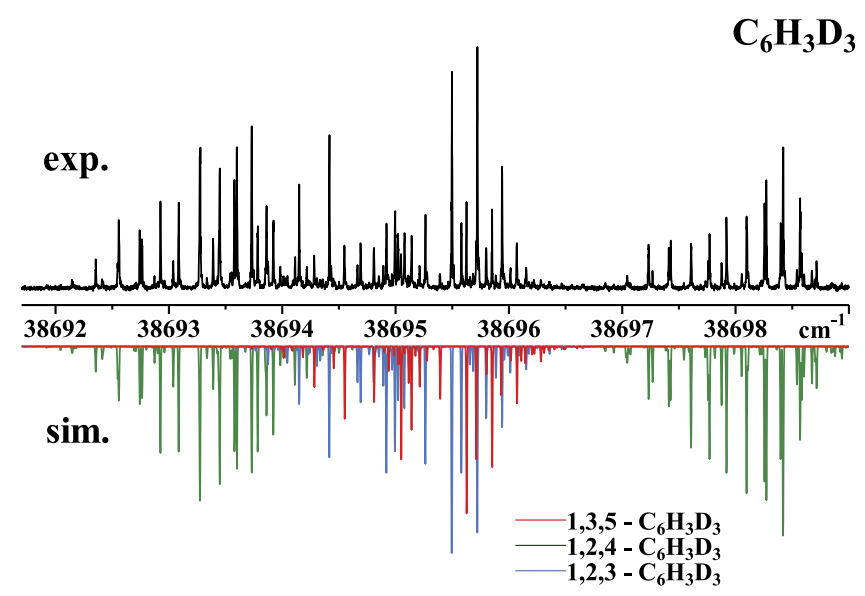

FIG. 4. REMPI excitation spectra of $\mathrm{C}_{6} \mathrm{H}_{3} \mathrm{D}_{3}$. 
6a

6b
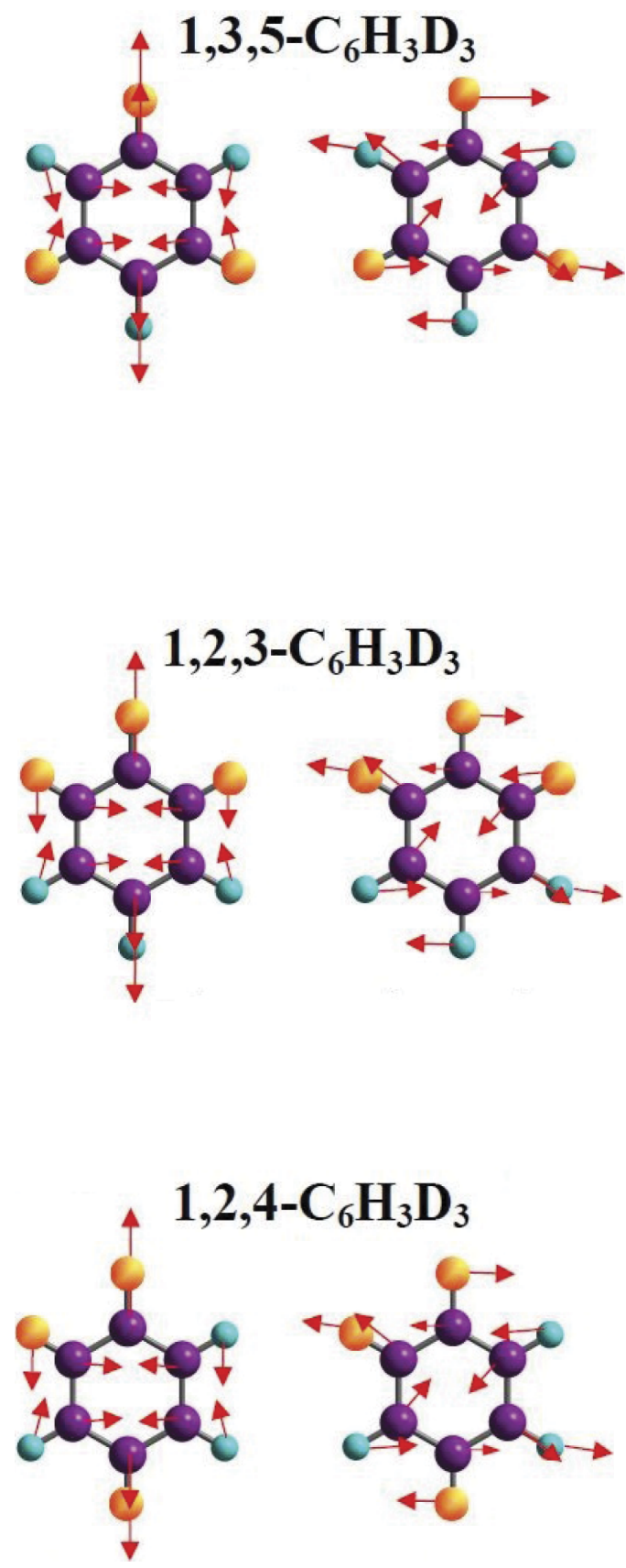

FIG. 5. Normal coordinates of $6 \mathrm{a}$ and $6 \mathrm{~b}$ vibrations of three $\mathrm{C}_{6} \mathrm{H}_{3} \mathrm{D}_{3}$ isotopomers.

$H_{r}$ is the term on a rigid rotor and is expressed as

$$
H_{r}=\frac{J_{x}^{2}}{2 I_{x}}+\frac{J_{y}^{2}}{2 I_{y}}+\frac{J_{z}^{2}}{2 I_{z}}
$$

where $J_{x}, J_{y}$, and $J_{z}$ are the components of total angular momentum, and $I_{x}, I_{y}$, and $I_{z}$ are the moments of inertia. It is also expressed using the rotational constants

$$
\begin{aligned}
H_{r}= & A J_{a}^{2}+B J_{b}^{2}+C J_{c}^{2} \\
= & \frac{1}{2}(A+B) J^{2}+\left[C-\frac{1}{2}(A+B)\right] J_{c}^{2} \\
& +\frac{1}{4}(A-B)\left(J_{+}^{2}+J_{-}^{2}\right) .
\end{aligned}
$$
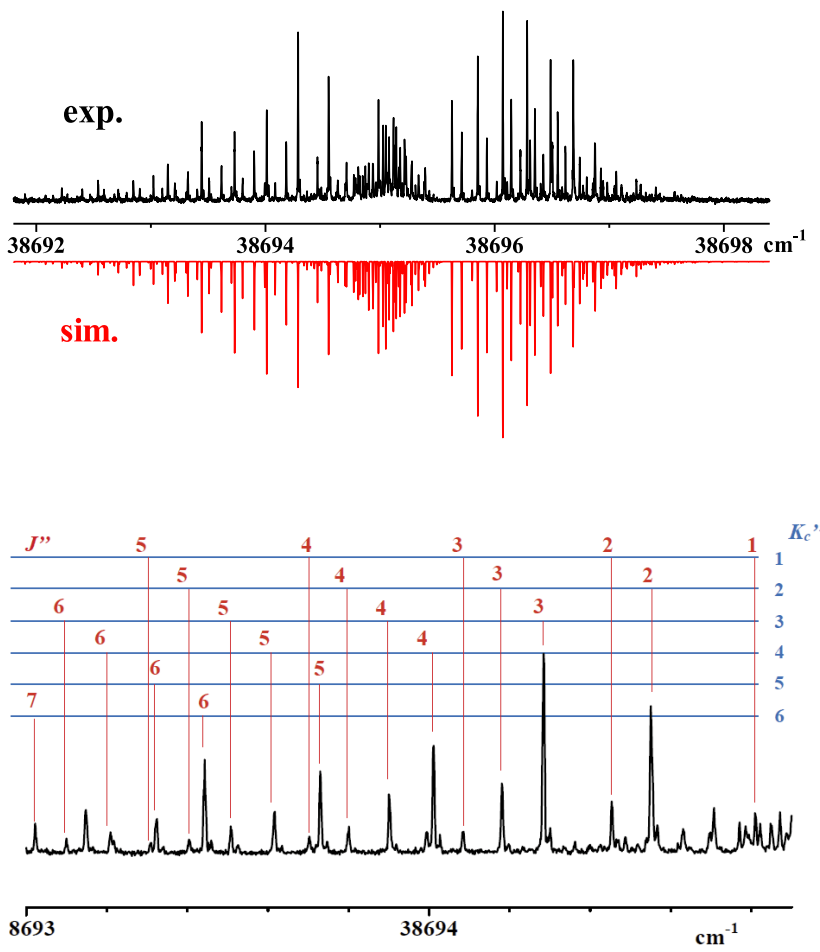

FIG. 6. REMPI excitation spectrum of $1,3,5-\mathrm{C}_{6} \mathrm{H}_{3} \mathrm{D}_{3}$.

The relationship between the molecular axes $x, y, z$ and the rotational principal axes $a, b, c$ is complicated and depends on the symmetry.

$H_{v}$ is the term of harmonic vibrations. $H^{\prime}$ is the term of perturbation involving the vibrational angular momentum and is given by

$$
H^{\prime}=-\frac{P_{x} J_{x}}{I_{x}}-\frac{P_{y} J_{y}}{I_{y}}-\frac{P_{z} J_{z}}{I_{z}}+\frac{P_{x}^{2}}{2 I_{x}}+\frac{P_{y}^{2}}{2 I_{y}}+\frac{P_{z}^{2}}{2 I_{z}} .
$$

The Coriolis interaction between $6 \mathrm{a}$ and $6 \mathrm{~b}$ arises from the $P_{z}$ terms. Assuming that the $P_{z}^{2}$ term is negligibly small, we obtain

$$
H^{\prime}=-\frac{P_{z} J_{z}}{I_{z}}=-2 C \zeta_{6 \mathrm{a}, 6 \mathrm{~b}}^{z}\left[Q_{6 \mathrm{a}} P_{6 \mathrm{~b}}-Q_{6 \mathrm{~b}} P_{6 \mathrm{a}}\right] .
$$

The experimental Coriolis parameter $\xi_{6 \mathrm{a}, 6 \mathrm{~b}}^{c}$ for level energy shifts is defined by

$$
\xi_{6 \mathrm{a}, 6 \mathrm{~b}}^{c}=\left|2 C \zeta_{6 \mathrm{a}, 6 \mathrm{~b}}^{z} \Omega\right| .
$$

$\Omega$ is given by

$$
\Omega=\frac{1}{2}\left(\sqrt{\frac{v_{6 \mathrm{a}}}{v_{6 \mathrm{~b}}}}+\sqrt{\frac{v_{6 \mathrm{~b}}}{v_{6 \mathrm{a}}}}\right)
$$

and the value can be estimated to be equal to one.

First we obtained the $\xi_{6 \mathrm{a}, 6 \mathrm{~b}}^{c}$ value using a least-squares fit of the transition wavenumbers of observed spectral lines for the $6 \mathrm{a}_{0}^{1}$ and $6 \mathrm{~b}_{0}^{1}$ bands of deuterated benzenes. In this case, the selection rules of Coriolis interaction about the $c$ axis are $\Delta J=0, \Delta K_{c}=0$. The level energies are obtained by diagonalizing the matrix 


$$
\left(\begin{array}{cc}
G\left(6 \mathrm{a}^{1}\right)+F\left(J, K_{a}, K_{c}\right) & -i \xi_{6 \mathrm{a}, \mathrm{b}}^{c} K_{c} \\
i \xi_{6 \mathrm{a}, 6 \mathrm{~b}}^{c} K_{c} & G\left(6 \mathrm{~b}^{1}\right)+F\left(J, K_{a}, K_{c}\right)
\end{array}\right),
$$

where $G$ and $F$ are the vibrational and rotational term values, respectively. $K_{a}$ is the quantum number of the $a$ axis component of the total angular momentum. The results are shown in Fig. 7. It can be seen that $\xi_{6 \mathrm{a}, 6 \mathrm{~b}}^{z}$ proportionally changes with the number of $\mathrm{D}$ atoms $\left(\mathrm{N}_{\mathrm{D}}\right)$.

Here, we consider the atomic mass dependence of $C$ and $\zeta_{6 \mathrm{a}, 6 \mathrm{~b}}^{z}$. The rotational constant $C$ is the reciprocal of the moment of inertia about the out-of-plane axis $I_{z}$, so that the change is expected to be approximately proportional to $\mathrm{N}_{\mathrm{D}}$. As for $\zeta_{6 \mathrm{a}, 6 \mathrm{~b}}^{z}$, the following equation can be derived from Eqs. (3) and (6):

$\zeta_{6 \mathrm{a}, 6 \mathrm{~b}}^{z}=\sum_{n} \frac{m_{n}}{\left(\mu_{6 \mathrm{a}}\right)^{1 / 2}\left(\mu_{6 \mathrm{~b}}\right)^{1 / 2}}\left(X_{6 \mathrm{a}, n} Y_{6 \mathrm{~b}, n}-Y_{6 \mathrm{a}, n} X_{6 \mathrm{~b}, n}\right)$,

where $\mu_{6 \mathrm{a}}$ and $\mu_{6 \mathrm{~b}}$ are the reduced masses for normal vibrations of $6 a$ and $6 b$, respectively. If we assume that the displacements and reduced mass are identical for all $\mathrm{H} / \mathrm{D}$ isotopomers, the difference of $\zeta_{6 \mathrm{a}, 6 \mathrm{~b}}^{z}$ between $\mathrm{C}_{6} \mathrm{H}_{6}$ and an isotopomer is approximately presented by

$$
\begin{aligned}
\zeta_{6 \mathrm{a}, 6 \mathrm{~b}}^{z}-\zeta_{6 \mathrm{a}, 6 \mathrm{~b}}^{\prime \prime z}= & \frac{1}{\left(\mu_{6 \mathrm{a}}\right)^{1 / 2}\left(\mu_{6 \mathrm{~b}}\right)^{1 / 2}} \\
& \times \sum_{n^{\prime}}^{z}\left[\Delta m_{n^{\prime}}\left(X_{6 \mathrm{a}, n^{\prime}} Y_{6 \mathrm{~b}, n^{\prime}}-Y_{6 \mathrm{a}, n^{\prime}} X_{6 \mathrm{~b}, n^{\prime}}\right)\right] .
\end{aligned}
$$

Here, $\zeta_{6 \mathrm{a}, 6 \mathrm{~b}}^{\prime} z_{\text {and }} \zeta^{\prime \prime} z_{6 \mathrm{a}, 6 \mathrm{~b}}$ are the Coriolis zeta constants of a substituted molecule and of $\mathrm{C}_{6} \mathrm{H}_{6}$, respectively. $n^{\prime}$ represents the deuterated nuclei, and $\Delta m_{n^{\prime}}$ is the change of nuclear mass of $n^{\prime}$ in the substitution. This indicates that the change in $\zeta_{6 \mathrm{a}, 6 \mathrm{~b}}^{z}$ by isotopomers is proportional to $\mathrm{N}_{\mathrm{D}}$. The $\xi_{6 \mathrm{a}, 6 \mathrm{~b}}^{c}$ value is therefore expected to depend on the square of $N_{D}$. The change in $C$ and $\zeta_{6 \mathrm{a}, 6 \mathrm{~b}}^{z}$, however, is very small compared with their own values. It is therefore concluded that $\xi_{6 \mathrm{a}, 6 \mathrm{~b}}^{c}$ is approximately proportional to $\mathrm{N}_{\mathrm{D}}$. We could obtain the atomic coordinates and displacements for $6 \mathrm{a}$ and $6 \mathrm{~b}$ by the vibrational calculation, explained in Section III A 1, and finally estimated

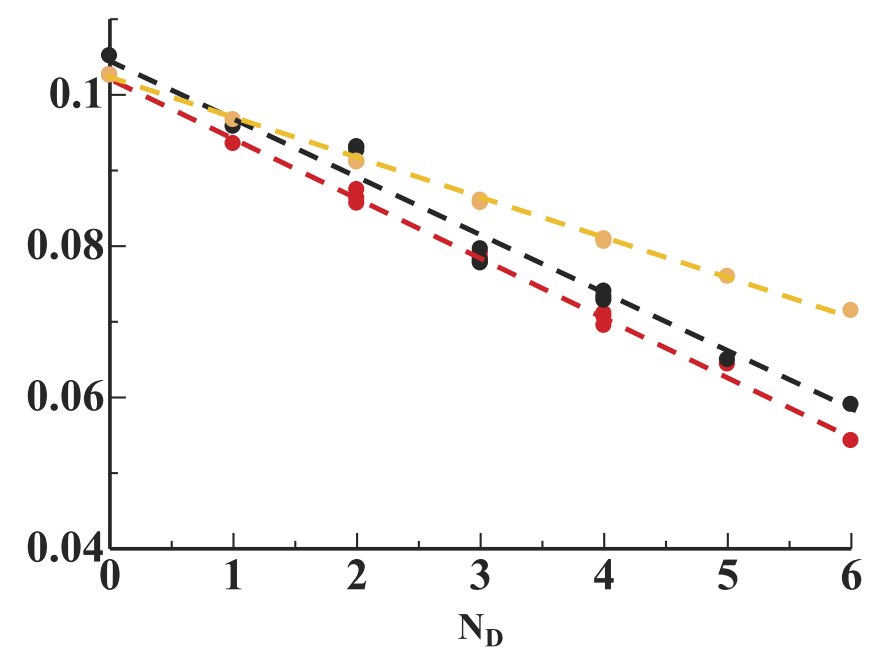

FIG. 7. $\mathrm{N}_{\mathrm{D}}$ dependence of the Coriolis parameter, $\xi_{6 \mathrm{a}, 6 \mathrm{~b}}^{c}$. Black: $\xi_{6 \mathrm{a}, 6 \mathrm{~b}}^{c}$ (Obs.), red: $\xi_{6 \mathrm{a}, 6 \mathrm{~b}}^{c}$ (Calc.) with each $Q_{6}$, and orange: $\xi_{6 \mathrm{a}, 6 \mathrm{~b}}^{c}$ (Calc.) fixed $Q_{6}$ of $\mathrm{C}_{6} \mathrm{H}_{6}$. the $\xi_{6 \mathrm{a}, 6 \mathrm{~b}}^{c}$ values of all isotopomers. The results are also shown in Fig. 7. These calculated values are in good agreement with the experimental ones. It should be noted that the changes in normal coordinates with isotopomers possibly affect the $\zeta_{6 \mathrm{a}, 6 \mathrm{~b}}^{z}$ value. The change in the calculated values using only the normal coordinate of $\mathrm{C}_{6} \mathrm{H}_{6}$ was significantly smaller than that using each individual normal coordinate of deuterated benzenes. Even so, it has been shown that $\zeta_{6 \mathrm{a}, 6 \mathrm{~b}}^{z}$ decreases proportionally with $\mathrm{N}_{\mathrm{D}}$.

The linear dependence of the Coriolis parameter on the $\mathrm{N}_{\mathrm{D}}$, however, is not always valid. According to the calculation using Gaussian 09, the displacement and reduced mass of $6 \mathrm{a}$ and $6 \mathrm{~b}$ do not vary much by deuterium substitution. This is because the displacements of $6 a$ and $6 b$ consist mainly of ring deformation and do not change much by deuterium substitution. On the other hand, if we calculate the modes which contain sufficient H/D nuclei displacements, the reduced mass and displacement will be quite different by substitution and Eq. (16) does not hold.

\section{CONCLUSIONS}

For all deuterated benzenes, we analyzed the vibrational and rotational structures of the $6 a^{1}$ and $6 b^{1}$ vibrational levels in the $S_{1}$ state. Although the two levels are degenerate in $\mathrm{C}_{6} \mathrm{H}_{6}$, $\mathrm{C}_{6} \mathrm{D}_{6}$, and $1,3,5-\mathrm{C}_{6} \mathrm{H}_{3} \mathrm{D}_{3}$, they are split by $2-5 \mathrm{~cm}^{-1}$ in other isotopomers. The results of theoretical calculation are in good agreement with our observations, and are useful to identify the observed spectral bands. The rotational constants were shown to be appreciably different between the $6 \mathrm{a}^{1}$ and $6 \mathrm{~b}^{1}$ vibrational levels. We suggest that the mean molecular structures in these levels depend on their normal coordinates and anharmonicity in the potential energy. The rotational levels are shifted by Coriolis interaction between these two levels.

Spectral analysis showed that the Coriolis parameter $\xi_{6 \mathrm{a}, 6 \mathrm{~b}}^{c}$ decreased with $\mathrm{N}_{\mathrm{D}}$. This tendency was understood by theoretical consideration and was verified by model calculations based on the molecular structure and normal coordinates of $6 \mathrm{a}$ and $6 \mathrm{~b}$ modes. The Coriolis zeta constant delicately varies with the normal coordinates.

\section{ACKNOWLEDGMENTS}

This work was supported by the Joint studies Program (2012-2014) of the Institute for Molecular Science.

\section{APPENDIX: NUCLEAR SPIN STATISTICS}

The intensity of each rotational line is proportional to the multiplicity of nuclear spin levels. $\mathrm{H}$ and $\mathrm{D}$ nuclei possess nuclear spins of $I=1 / 2$ and $I=1$, respectively, so that the multiplicity depends on the number of $\mathrm{D}$ atoms and substituted positions. We represent the nuclear wave function of a molecule as

$$
\Psi_{n u c}=\Psi_{v} \Psi_{r} \Psi_{I}
$$

Here, $\Psi_{v}, \Psi_{r}$, and $\Psi_{I}$ are the vibrational, rotational and nuclear spin parts, respectively. An $\mathrm{H}$ nucleus is a fermion 
TABLE II. Symmetry of wave functions and nuclear spin statistics of deuterated isotopomers.

\begin{tabular}{|c|c|c|c|c|c|}
\hline & Symmetry & $\Psi_{I}$ & $\Psi_{n и с}$ & eе:ео:оe:oo & $2^{\mathrm{N}} 3^{6-\mathrm{N}}$ \\
\hline $\mathrm{C}_{6} \mathrm{H}_{6}$ & $D_{6 h}$ & $13 A_{1}+A_{2}+7 B_{1}+3 B_{2}+9 E_{1}+11 E_{2}$ & $B_{1}$ & & 64 \\
\hline $\mathrm{C}_{6} \mathrm{H}_{5} \mathrm{D}$ & $C_{2 v}$ & $60 A+36 B$ & $A$ & $5: 5: 3: 3$ & 96 \\
\hline$o-\mathrm{C}_{6} \mathrm{H}_{4} \mathrm{D}_{2}$ & $C_{2 v}$ & $78 A+66 B$ & $A$ & 13:13:11:11 & 144 \\
\hline$m-\mathrm{C}_{6} \mathrm{H}_{4} \mathrm{D}_{2}$ & $C_{2 v}$ & $84 A+60 B$ & $B$ & $5: 7: 7: 5$ & 144 \\
\hline$p-\mathrm{C}_{6} \mathrm{H}_{4} \mathrm{D}_{2}$ & $D_{2 h}$ & $51 A_{1}+27 B_{1}+27 B_{2}+39 B_{3}$ & $A_{1}$ & $17: 13: 9: 9$ & 144 \\
\hline $1,3,5-\mathrm{C}_{6} \mathrm{H}_{3} \mathrm{D}_{3}$ & $D_{3 h}$ & $56 A_{1}+20 A_{2}+70 E$ & $A_{2}$ & & 216 \\
\hline $1,2,3-\mathrm{C}_{6} \mathrm{H}_{3} \mathrm{D}_{3}$ & $C_{2 v}$ & $126 A+90 B$ & $B$ & $5: 7: 7: 5$ & 216 \\
\hline $1,2,4-\mathrm{C}_{6} \mathrm{H}_{3} \mathrm{D}_{3}$ & $C_{s}$ & $\ldots$ & $\ldots$ & $1: 1: 1: 1$ & 216 \\
\hline$o-\mathrm{C}_{6} \mathrm{H}_{2} \mathrm{D}_{4}$ & $C_{2 v}$ & $171 A+153 B$ & $B$ & $17: 19: 19: 17$ & 324 \\
\hline$m-\mathrm{C}_{6} \mathrm{H}_{2} \mathrm{D}_{4}$ & $C_{2 v}$ & $189 A+135 B$ & $B$ & $5: 5: 7: 7$ & 324 \\
\hline$p-\mathrm{C}_{6} \mathrm{H}_{2} \mathrm{D}_{4}$ & $D_{2 h}$ & $99 A_{1}+72 B_{1}+72 B_{2}+81 B_{3}$ & $B_{3}$ & $9: 8: 8: 11$ & 324 \\
\hline $\mathrm{C}_{6} \mathrm{HD}_{5}$ & $C_{2 v}$ & $270 A+216 B$ & $A$ & $5: 4: 4: 5$ & 486 \\
\hline $\mathrm{C}_{6} \mathrm{D}_{6}$ & $D_{6 h}$ & $92 A_{1}+38 A_{2}+73 B_{1}+46 B_{2}+116 E_{1}+124 E_{2}$ & $A_{1}$ & & 729 \\
\hline
\end{tabular}

TABLE III. Symmetry of wave functions and nuclear spin statistics of symmetric-top isotopomers ( $p$ is natural number).

\begin{tabular}{lccccc}
\hline \hline Isotopomer & $K_{C}$ & $J$ & $\Psi_{r}$ & $\Psi_{I}$ & $S_{J, K_{C}}$ \\
\hline $\mathrm{C}_{6} \mathrm{H}_{6}$ & $6 p$ & & $A_{1}+A_{2}$ & $B_{1}+B_{2}$ & 10 \\
& $6 p-5,6 p-1$ & & $E_{1}$ & $E_{2}$ & 11 \\
& $6 p-4,6 p-2$ & & $E_{2}$ & $E_{1}$ & 9 \\
& $6 p-3$ & & $B_{1}+B_{2}$ & $A_{1}+A_{2}$ & 14 \\
& 0 & $J=$ even & $A_{1}$ & $B_{1}$ & 7 \\
& & $J=$ odd & $A_{2}$ & $B_{2}$ & 3 \\
\hline $1,3,5-\mathrm{C}_{6} \mathrm{H}_{3} \mathrm{D}_{3}$ & $3 p$ & & $A_{1}+A_{2}$ & $A_{2}+A_{1}$ & 76 \\
& & & & & \\
& $3 p-1,3 p-2$ & & $A_{1}$ & $A_{2}$ & 70 \\
& 0 & $J=$ even & $A_{2}$ & $A_{1}$ & 56 \\
\hline $\mathrm{C}_{6} \mathrm{D}_{6}$ & & $J=$ odd & $A_{1}+A_{2}$ & $A_{1}+A_{2}$ & 130 \\
& $6 p$ & & $E_{1}$ & $E_{1}$ & 116 \\
& $6 p-5,6 p-1$ & & $E_{2}$ & $E_{2}$ & 124 \\
& $6 p-4,6 p-2$ & & $B_{1}+B_{2}$ & $B_{1}+B_{2}$ & 119 \\
& $6 p-3$ & $A_{1}$ & $A_{1}$ & 92 \\
& 0 & $A_{2}$ & $A_{2}$ & 38 \\
\hline \hline
\end{tabular}

whose wave function is anti-symmetric (changes the sign with respect to exchange of the particle), while a D nucleus is a boson that has a symmetric wave function. If we consider the zero-vibrational level in the electronic ground state, $\Psi_{v}$ is symmetric. The symmetry of $\Psi_{I}$, therefore, depends on $\Psi_{r}$. In Table II, the symmetries (irreducible representations) of $\Psi_{I}$ and $\Psi_{n u c}$ are listed for all deuterated benzenes. We ignore the parity here because the $\sigma_{h}$ operation never exchanges the particles in a planar molecule. ee:eo:oe:oo represents the ratio of nuclear spin state multiplicity for the odd or even $K_{a} K_{c}$ rotational levels. The total number of the nuclear spin states is $2^{\mathrm{N}} 3^{6-\mathrm{N}}$, where $\mathrm{N}$ is the number of $\mathrm{H}$ atoms.

For the symmetric-top molecules such as $\mathrm{C}_{6} \mathrm{H}_{6}$, 1,3,5- $\mathrm{C}_{6} \mathrm{H}_{3} \mathrm{D}_{3}$, and $\mathrm{C}_{6} \mathrm{D}_{6}$, the nuclear spin statistics are somewhat complicated because $\Psi_{I}$ includes $E$ symmetry (second-order irreducible representation). The nuclear spin state multiplicity $S_{J, K c}$ for the three isotopomers is presented in Table III. The line intensity strongly depends on the rotational quantum numbers $J$ and $K_{c}$.
${ }^{1}$ C. S. Parmenter, Adv. Chem. Phys. 22, 365 (1972).

${ }^{2}$ P. Avouris, W. M. Gelbart, and M. A. El-Sayed, Chem. Rev. 77, 793 (1977)

${ }^{3}$ J. H. Callomon, T. M. Dunn, and I. M. Mills, Philos. Trans. R. Soc., A 259, 499 (1966).

${ }^{4}$ T. Suzuki and M. Ito, J. Chem. Phys. 91, 4564 (1989).

${ }^{5}$ S. Kunishige, T. Katori, M. Baba, M. Nakajima, and Y. Endo, J. Chem. Phys. 143, 244302 (2015).

${ }^{6}$ H. Sieber, E. Riedle, and H. J. Neusser, J. Chem. Phys. 89, 4620 (1988).

${ }^{7}$ M. Okruss, R. Müller, and A. Hese, J. Mol. Spectrosc. 193, 293 (1999).

${ }^{8}$ E. Riedle, A. Beil, D. Luckhaus, and M. Quack, Mol. Phys. 81, 1 (1994).

${ }^{9}$ E. B. Wilson, Jr., Phys. Rev. 45, 706 (1934).

${ }^{10} \mathrm{G}$. Herzberg, Molecular Spectra and Molecular Structure. II. Infrared and Raman Spectra of Polyatomic Molecules (Van Nostrand Reinhold, New York, 1945)

${ }^{11}$ S. Kunishige, T. Katori, M. Kawabata, T. Yamanaka, and M. Baba, J. Chem. Phys. 143, 244304 (2015).

${ }^{12}$ M. Misono, J. Wang, M. Ushino, M. Okubo, H. Katô, M. Baba, and S. Nagakura, J. Chem. Phys. 116, 162 (2002).

${ }^{13}$ A. Doi, S. Kasahara, H. Katô, and M. Baba, J. Chem. Phys. 120, 6439 (2004).

${ }^{14}$ A. Doi, M. Baba, S. Kasahara, and H. Katô, J. Mol. Spectrosc. 227, 180 (2004).

${ }^{15}$ H. Hayashi and Y. Ohshima, Chem. Phys. 419, 131 (2013).

${ }^{16} \mathrm{H}$. Hayashi and Y. Ohshima, J. Phys. Chem. A 117, 9819 (2013).

${ }^{17}$ I. M. Mills, Pure Appl. Chem. 11, 325 (1965). 
${ }^{18}$ M. Oldani and A. Bauder, Chem. Phys. Lett. 108, 7 (1984).

${ }^{19}$ A Program for Simulating Rotational Structure, C. M. Western, University of Bristol, 2012, http://pgopher.chm.bris.ac.uk.

${ }^{20}$ J. Pliva, J. W. C. Johns, and L. Goodman, J. Mol. Spectrosc. 140, 214 (1990).

${ }^{21}$ M. Baba, Y. Kowaka, U. Nagashima, T. Ishimoto, H. Goto, and N. Nakayama, J. Chem. Phys. 135, 054305 (2011).

${ }^{22}$ M. J. Frisch, G. W. Trucks, H. B. Schlegel, G. E. Scuseria, M. A. Robb, J. R. Cheeseman, G. Scalmani, V. Barone, B. Mennucci, G. A. Petersson, H. Nakatsuji, M. Caricato, X. Li, H. P. Hratchian, A. F. Izmaylov, J. Bloino, G. Zheng, J. L. Sonnenberg, M. Hada, M. Ehara, K. Toyota, R. Fukuda, J.
Hasegawa, M. Ishida, T. Nakajima, Y. Honda, O. Kitao, H. Nakai, T. Vreven, J. A. Montgomery, Jr., J. E. Peralta, F. Ogliaro, M. Bearpark, J. J. Heyd, E. Brothers, K. N. Kudin, V. N. Staroverov, T. Keith, R. Kobayashi, J. Normand, K. Raghavachari, A. Rendell, J. C. Burant, S. S. Iyengar, J. Tomasi, M. Cossi, N. Rega, J. M. Millam, M. Klene, J. E. Knox, J. B. Cross, V. Bakken, C. Adamo, J. Jaramillo, R. Gomperts, R. E. Stratmann, O. Yazyev, A. J. Austin, R. Cammi, C. Pomelli, J. W. Ochterski, R. L. Martin, K. Morokuma, V. G. Zakrzewski, G. A. Voth, P. Salvador, J. J. Dannenberg, S. Dapprich, A. D. Daniels, O. Farkas, J. B. Foresman, J. V. Ortiz, J. Cioslowski, and D. J. Fox, Gaussian 09, Revision C.01, Gaussian, Inc., Wallingford CT, 2010. 